Sādhanā Vol. 38, Part 5, October 2013, pp. 971-997. (C) Indian Academy of Sciences

\title{
Structural integrity aspects of reactor safety
}

\author{
K K VAZE \\ Reactor Design and Development Group, Bhabha Atomic Research Centre (BARC), \\ Mumbai, 400 085, India \\ e-mail:kkvaze@barc.gov.in
}

\begin{abstract}
The overall goal of nuclear power plant safety is to protect individuals, society and the environment from undue radiological hazard so that nuclear power production does not significantly add to the health risks to which individuals and society are already exposed. This paper addresses the safety principles followed during the design phase of life cycle of a nuclear power plant. The principles followed such as safety classification, design rules based on failure modes, detailed stress analysis, stress categorization, consideration of design basis events, failure probability, flaw tolerance, leak-before-break are described. Engineering structures always contain flaws, albeit of very small size. Fatigue and fracture are the two important failure modes affected by flaws. Thus flaw tolerance becomes very important. This is assessed by applying fracture mechanics principles. The R6 procedure, which is used for evaluation of structures containing flaws, has been incorporated in the software BARC-R6. Improvements by way of shell-nozzle junction pull-out, adoption of hot wire GTAW with narrow gap technique have been brought out. Post Fukushima incidence, resistance to seismic loading and containment design have assumed great importance. The paper describes these aspects in detail. Regulatory aspects of seismic design regarding siting, Seismic margin assessment, base isolation, retrofitting are the aspects covered under seismic design. Under the action of seismic loading, the piping in a nuclear power plant piping is vulnerable to a phenomenon called ratcheting. The process of seismic margin assessment and consideration of ratchetting has been backed up by a large experimental data. The experiments carried out on structures and piping components form a part of the paper.
\end{abstract}

Keywords. Structural integrity; loading levels; leak before break; fracture; fatigue; seismic design.

\section{Introduction}

This paper addresses the safety principles followed during the design phase of life cycle of a nuclear power plant. Although there are many aspects of reactor safety, the ultimate safety of a nuclear reactor hinges on structural integrity of the components. The principles followed such as safety classification, design rules based on failure modes, detailed stress analysis, stress categorization, consideration of design basis events, failure probability, flaw tolerance, leakbefore-break are described. 
A large experimental programme supported the structural integrity demonstration. While satisfaction of leak-before-break (LBB) criterion was demonstrated by way of a large number of fatigue/fracture tests; improvements by way of adoption of hot wire Gas Tungsten Arc Welding (GTAW) with narrow gap technique have been quantified by residual stress measurement.

Resistance to seismic loading and containment design have assumed great importance after Fukushima accident. The paper describes these aspects in detail. Regulatory aspects of seismic design regarding siting, Seismic margin assessment, base isolation, retrofitting are the aspects covered under seismic design. Under the action of seismic loading, the piping in a nuclear power plant piping is vulnerable to a phenomenon called ratcheting. The process of seismic margin assessment and consideration of ratchetting has been backed up by a large experimental data. The experiments carried out on structures and piping components form a part of the paper.

The containment building is the ultimate physical barrier between radioactive source inside the nuclear reactor core and the public at large. Apart from the internal pressure loading arising out of a postulated loss of coolant accident, the containment is also assessed for a postulated aircraft impact. A 1:4 scale model (BARCOM) will address the ultimate pressure carrying capacity of the containment.

\section{Structural design - Guiding principles}

\subsection{Safety classification}

The process of structural design begins with Safety Classification. The guiding principles for this are (IAEA 2013):

- Fulfilment of the following fundamental safety functions for a nuclear power plant shall be ensured for all plant states: (i) control of reactivity, (ii) removal of heat from the reactor and from the fuel store and (iii) confinement of radioactive material, shielding against radiation and control of planned radioactive releases, as well as limitation of accidental radioactive releases.

- All items important to safety shall be identified and shall be classified on the basis of their function and their safety significance.

- The engineering design rules for items important to safety at a nuclear power plant shall be specified and shall comply with the relevant national or international codes and standards and with proven engineering practices, with due account taken of their relevance to nuclear power technology.

The process of Safety Classification and assigning appropriate engineering design rules is followed meticulously in the design of nuclear power plant components. Among the three Safety Categories in which the structures, systems and components (SSC) are classified, the Safety category 1 applies to those SSCs which perform "Any function required to reach the controlled state after an anticipated operational occurrence or a design basis accident and whose failure, when challenged, would result in consequences of 'high' severity."

\subsection{Design code}

The code adopted for components belonging to Safety Class I is the ASME B\&PV Code, Section III (ASME B\&PV Code). 
The design rules of ASME Section III are based on:

(1) Failure mode orientation

(i) Identifying various failure modes,

(ii) Identifying the parameter causing the failure mode

(iii) Finding its critical value and

(iv) Formulate a 'design rule' separating the operating value of the parameter from its critical value by appropriate factor of safety;

(2) Design by analysis

This is based on the idea that if a proper stress analysis can be carried out then we can make a better, less conservative assessment of the design. A modern day finite element computer code is capable of carrying out stress analysis of very complex structures subjected to almost any type of loading.

(3) Stress categorization

The significance of stresses due to different loadings or stresses at different locations in a pressure vessel could be different. The stress, which is very localized in nature is not as detrimental as the stress in the cylindrical shell of a pressure vessel. This led to the categorization of stresses into Primary (P), Secondary (Q) and Peak (F). The stresses are also categorized as membrane and bending.

Combining the above two aspects, the design rules of Section III can be framed as shown in table 1.

The design rules given in the above table apply to the 'Design Conditions'. Deviations from Normal Operating Conditions are also considered and structural analysis is performed to evaluate the consequences of postulated design basis events.

\subsection{Design basis events (DBE)}

These are the set of events that serve as part of the basis for the establishment of design requirements for structures, systems and components SSCs within a facility. Design Basis events

Table 1. Design rules of section III.

\begin{tabular}{llll}
\hline Failure mode & Governing parameter & Critical value & Design rule \\
\hline Gross deformation by yielding & $\mathrm{P}_{\mathrm{m}}, \mathrm{P}_{\mathrm{b}}$ & $\mathrm{S}_{\mathrm{y}}, 1.5 \mathrm{~S}_{\mathrm{y}}$ & $\mathrm{P}_{\mathrm{m}} \leq \mathrm{S}_{\mathrm{m}}$ \\
& & $\mathrm{P}_{\mathrm{b}} \leq 1.5 \mathrm{~S}_{\mathrm{m}}$ \\
Tensile instability & $\mathrm{P}_{\mathrm{m}}, \mathrm{P}_{\mathrm{b}}$ & $\mathrm{S}_{\mathrm{u}}, 1.5 \mathrm{~S}_{\mathrm{u}}$ & $\left(\mathrm{P}_{\mathrm{L}}+\mathrm{P}_{\mathrm{b}}+\mathrm{Q}_{\mathrm{R}}\right) \leq 3 \mathrm{~S}_{\mathrm{m}}$ \\
Plastic cycling & $\mathrm{Q}_{\mathrm{rang}}$ & $2 \mathrm{~S}_{\mathrm{y}}$ & If $\sigma_{\mathrm{p}}>\sigma_{\mathrm{y}} / 2$, \\
Ratchetting & Const. $\sigma_{\mathrm{p}}$, Cyclic $\sigma_{\mathrm{t}}$ & $\sigma_{\mathrm{p}}, \sigma_{\mathrm{t}}$ combination & $\sigma_{\mathrm{p}}+1 / 4 \sigma_{\mathrm{t}} \leq \sigma_{\mathrm{y}}$ \\
& & & If $\sigma_{\mathrm{p}}<\sigma_{\mathrm{y}} / 2$, \\
& & & $\sigma_{\mathrm{p}} \cdot \sigma_{\mathrm{t}} \leq \sigma_{\mathrm{y}}^{2}$ \\
& & $\mathrm{~N}_{\mathrm{all}}$ & $\Sigma\left(\mathrm{n}_{i} / \mathrm{N}_{\mathrm{i}}\right) \leq 1$ \\
Fatigue & $\mathrm{S}_{\mathrm{a}}, \mathrm{n}$ & Fracture toughness & $\mathrm{K} \leq \mathrm{K}_{\mathrm{IC}} / \sqrt{ } 10$ \\
Brittle fracture & Stress intensity & $\mathrm{K}_{\mathrm{IC}}$ & \\
& factor, K & Geometry dependent & Use Ext. Pressure \\
Buckling & $\sigma_{\mathrm{c}}$ & & design charts \\
& & &
\end{tabular}


include normal operations, operational transients and certain accident conditions with postulated initiating events (PIE) considered in the design of the plant.

DBEs are classified on the basis of expected frequency of their occurrence. Events with large consequences are extremely rare while a frequent event can be accepted only if the consequences have a very low severity. A sufficiently broad spectrum of DBEs, which ensures that all relevant types of events are considered, forms the basis of design analysis.

Category 1- Normal operation and operational transients

Category 2- Moderate frequency

Category 3- Low frequency

Category 4- Multiple failures and rare events.

A partial list of design basis events considered is given below (AERB Safety Guide 2000):

\section{Category 1}

- Reactor start-up from cold to full power (FP)

- Reactor power operation

- Shutdown from FP to cold

- Reactor trip and restart before poison out

\section{Category 2}

- Loss of regulation

- Loss of external electrical load

- Turbine trip

- Loss of normal feed water flow

- Primary coolant pump trip

- Credible flow blockage

- Class IV electrical power supply failure

- Operating Basis Earthquake (OBE)

\section{Category 3}

- Rupture of PHT system piping up to double-ended guillotine break

- Failure of a coolant channel leading to Loss of Coolant Accident (LOCA)

- Steam system pipe break

- Loss of on-site electrical power supply (Class III, II or I)

- Safe Shutdown Earthquake (SSE)

- Design basis flood including tsunami

\section{Category 4}

- LOCA coupled with failure of emergency core cooling system

- Station blackout (simultaneous failure of Class II and Class IV electrical power supply) for specified duration

- SSE with LOCA

\subsection{Failure probability}

Failure is said to occur when the primary membrane stress intensity exceeds the ultimate tensile strength of the material Su. The failure probability will depend on the coefficient of variance 
associated with the material properties $\mathrm{Sy}$ and $\mathrm{Su}$, as well as the calculated stress intensities for the load combinations. Following assumptions are made:

The material properties Sy and Su have a coefficient of variance (COV) of 0.1 and the code specified value is the 5 percentile i.e., only $5 \%$ values fall below the specified value. This means that

$$
\text { Smean }=\operatorname{Smin}+1.64 * \mathrm{COV} * \text { Smean }
$$

Similarly, the loads (or stresses) have a coefficient of variation of 0.15 and for codal compliance we use the value, which is (mean + standard deviation).

With the above assumptions, the probability of failure is calculated as follows:

Material SA 516 Gr 70

Properties at $300^{\circ} \mathrm{C}$ :

- $\mathrm{Sm}=130.9 \mathrm{MPa}$

- Yield strength = 196.7 MPa

- Minimum tensile strength $=490 \mathrm{MPa}$

- $\mathrm{COV}$ for YS/UTS = 0.1

- Std. Dev. $=58.6 \mathrm{MPa}$

- Mean UTS = 586.1 MPa

With this data, the probability of failure works out to $5.3 \times 10^{-15}$, a very low value indeed and failure is not expected to occur unless there are flaws in the component.

\subsection{Flaw tolerance}

As stated earlier, the probable mode of failure will involve flaws. Engineering structures always contain flaws, albeit of very small size. ASME Section III, Appendix G requires postulation of a flaw which has a depth of $25 \%$ of thickness and length equal to 1.5 times the thickness, in spite of the fact that the probability that such a large flaw will be missed during inspection is very small. Thus flaw tolerance becomes very important. This is assessed by applying fracture mechanics principles. A number of methods are available to assess the integrity of flawed structures. The failure criterion in most of these methods is either fracture based or is plastic instability based. In order to ascertain the integrity of a flawed structure one has to perform two analyses, each based on the mentioned failure mode. The R6 method (Milne et al 1986) is a tool, which can perform analysis considering fracture and plastic instability together as failure criteria.

R6 is used to estimate;

- Limiting load to avoid failure of a structure containing a known or postulated flaw.

- The limiting flaw size of a structure subjected to a specified loading condition.

- The margins of reserve factors on the assessed condition, compared with the above two limiting conditions.

Structural integrity is ascertained on a 'Failure Assessment Diagram' (FAD). This diagram is divided in two parts by a segment called 'Failure Assessment Line' (FAL). The structure is assessed and plotted on this FAD.

The general procedure for performing an R6 analysis is listed below.

- Define all loads, flaw shape and size and calculate applied stress intensity factor $K_{I}$

- Define fracture toughness Kmat 


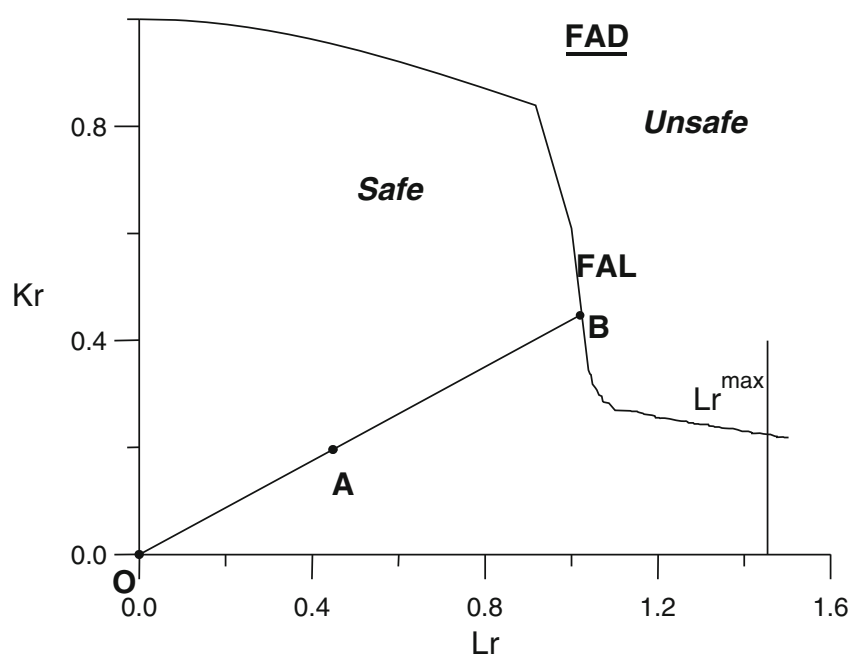

Figure 1. The Failure assessment diagram.

- Calculate $L_{r}^{\prime}=$ applied load/plastic yield load

- Calculate $K_{r}=K_{I}^{\prime} / K m a t$

- Plot all points on failure assessment diagram.

The structural integrity is assessed using a FAD as shown in the figure 1.

If the assessed point $\left(\mathrm{L}_{\mathrm{r}}^{\prime}, \mathrm{K}_{\mathrm{r}}^{\prime}\right)$ lies with in the area bounded by FAL and the axes, the structure is safe. The method has been used for demonstrating integrity of PHWR piping using a software.

\subsection{The BARC-R6 software (Rastogi et al 2001)}

The above procedure requires material data and solutions for limit load and stress intensity factors. BARC-R6 software has built-in database for a number of cases such as straight pipe/elbow with through-wall circumferential/axial or part circumference/axial crack.

\section{Leak-before-break}

One of the ways in which the decision to live with the defect can be aided is the demonstration of leak-before-break (LBB). A combination of ductile material, not so hostile environment and a reliable leak detection system is necessary for this.

This concept aims at the application of fracture mechanics principle to demonstrate that pipes are very unlikely to experience sudden catastrophic break without prior indication of leakage. LBB evaluation is divided in three stages:

In the first stage, it is shown that in view of the stringent specifications in material, design, fabrication, inspection and testing, there will be no crack initiation, thus avoiding the possibility of crack propagation.

In the second level of LBB evaluation, we postulate that a crack of certain length and depth has escaped detection. But, it can be shown that for the duration of plant life this crack will not grow enough to penetrate the wall, let alone cause catastrophic failure. 
In the third level, we postulate forced crack propagation to penetrate the wall and show that the resultant through-wall crack is stable, produces leakage in sufficient quantity to enable detection and corrective action can be taken before it becomes critical.

\subsection{Experimental programme (Singh et al 2008a; Chattopadhyay et al 2011; Raghava et al} 2008)

For validating the LBB argument, a large number of fatigue/fracture tests have been carried out under the Programme on Component Integrity Testing (figures 2 and 3). The effect of high temperature and pressure loading was evaluated by conducting appropriate tests (Chattopadhyay et al 2011). Following conclusions could be drawn:

(i) The number of cycles required for the postulated crack to reach through-wall is very large compared to the number of cycles anticipated during service. This satisfies the second stage of LBB evaluation (figure 4).

(ii) The number of cycles required for crack initiation can be calculated to a good accuracy using the characteristic distance approach (figure 4).

(iii) Paris constants obtained from the standard CT/TPB specimens may be used directly for crack growth rate analysis of pipes (figure 5).

(iv) Irrespective of the initial value, the aspect ratio of the crack when it becomes throughwall is limited to about 4.0 (figures 6 and 7).

(v) The maximum load sustained by the pipes having a through-wall crack resulting from previous fatigue loading is much more than the maximum load anticipated during service. This satisfies the third stage of LBB evaluation.

(vi) New correlations were developed for limit load of piping components for improved integrity assessment (Chattopadhyay et al 2011).

\subsection{Probabilistic leak before break (LBB) studies}

A probabilistic analysis of primary heat transport system of Indian Pressurized Heavy Water reactor was performed (Rastogi et al 2004). Probability of failure was obtained with crack growth

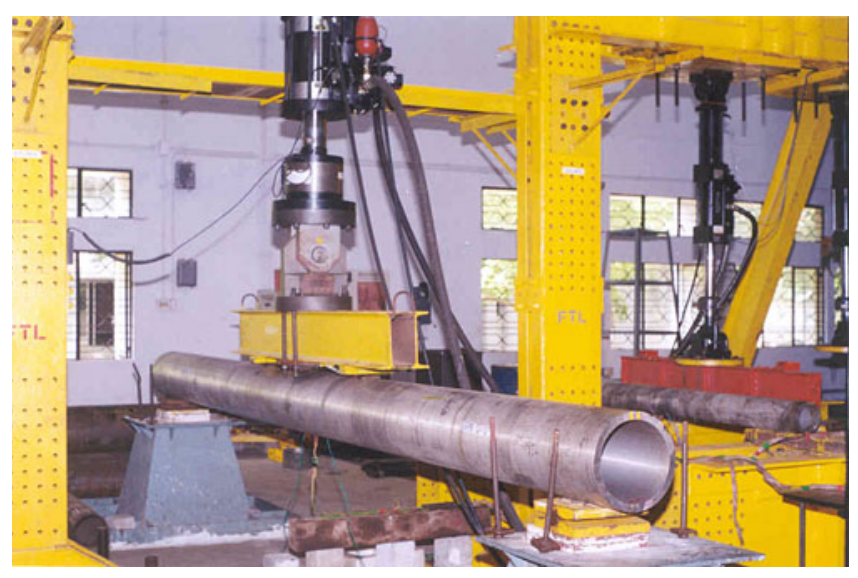

Figure 2. Straight Pipe being subjected to cyclic loading. 


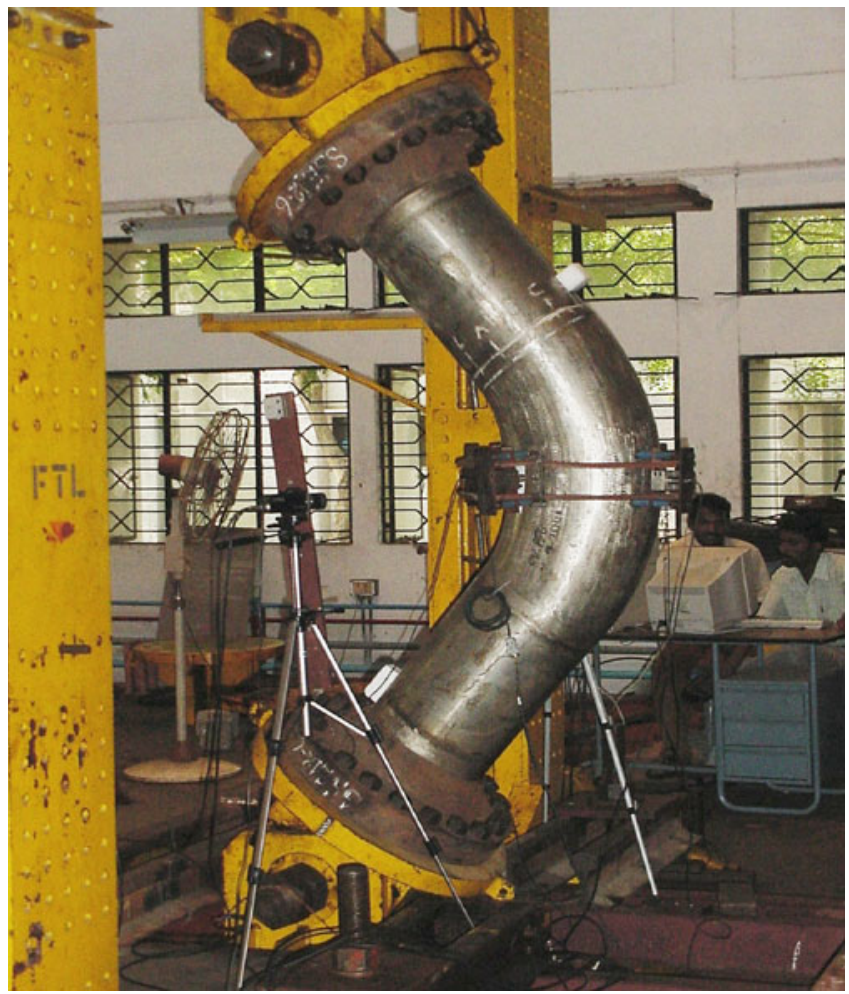

Figure 3. Piping Elbow being subjected to cyclic loading.

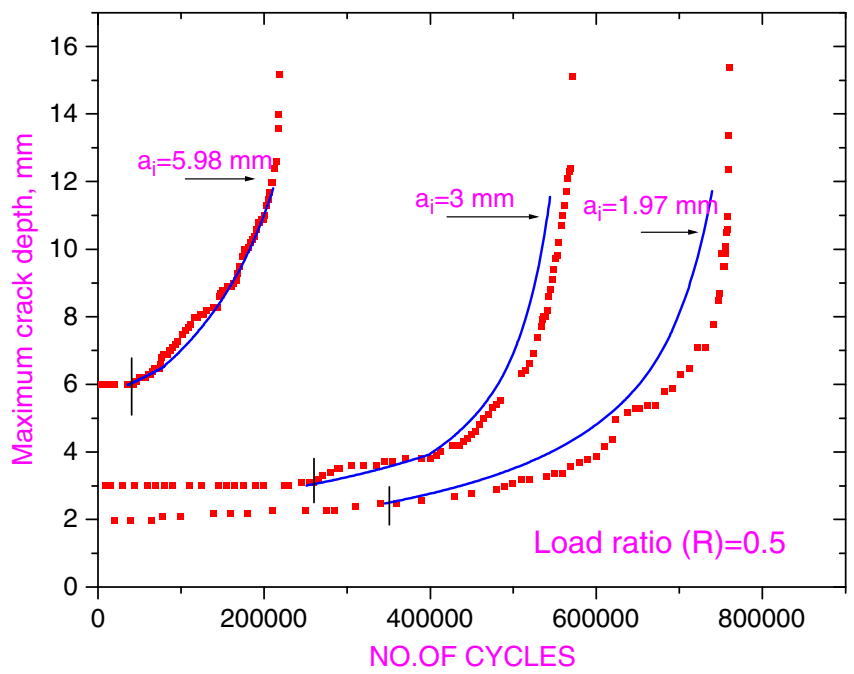

Figure 4. Comparison of analytical and experimental crack growth. 


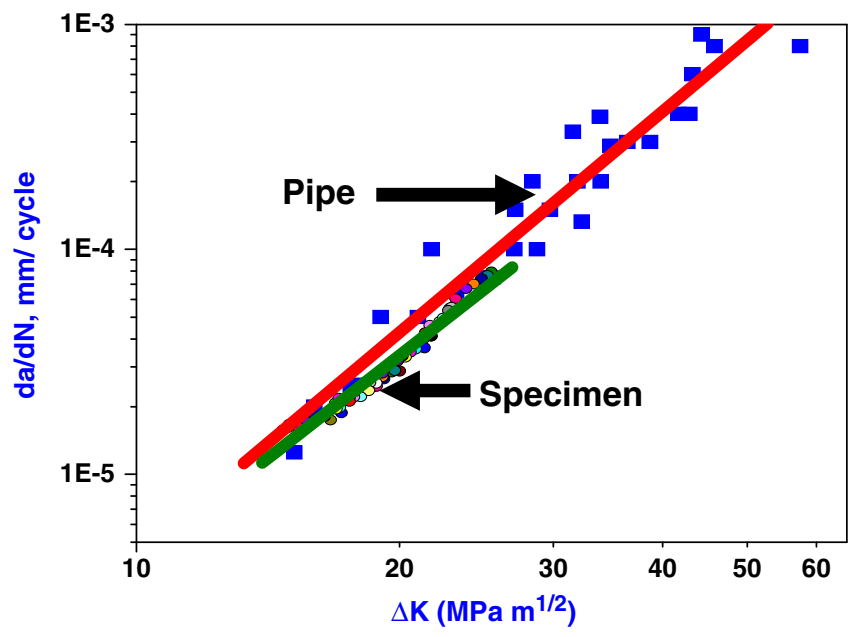

Figure 5. Comparison of Paris constants - Pipe vs specimen.
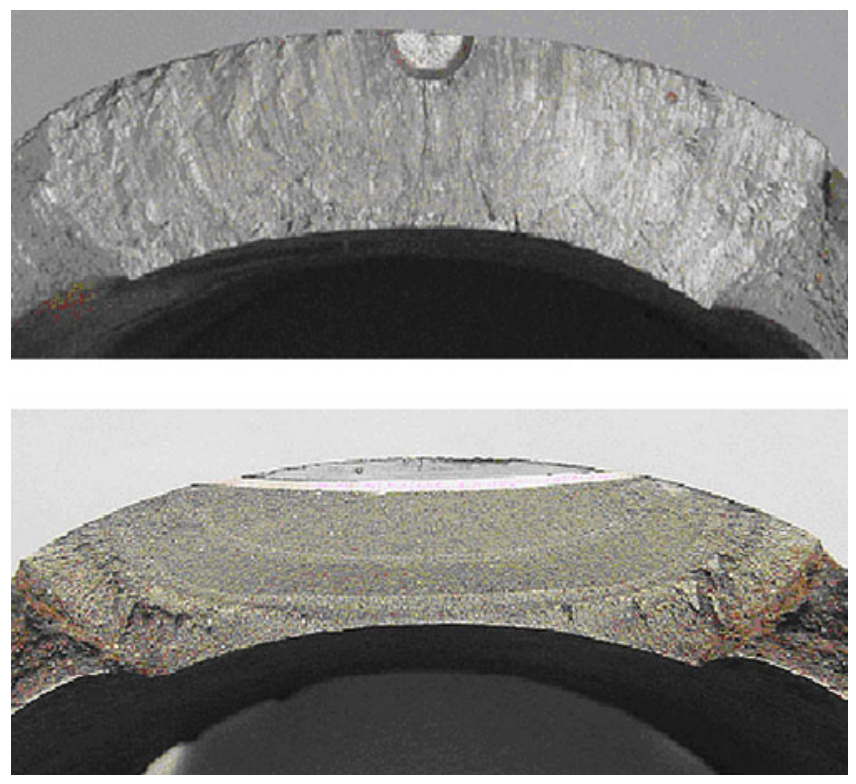

Figure 6. Initial cracks - aspect ratios of 2 and 12 .

initiation as the limiting condition. The variability in the crack size and material properties (tensile and fracture) was considered. Various methods of probability estimation were used and their equivalence was demonstrated. The probability of failure was obtained using classical Monte Carlo method, Monte Carlo with importance sampling, First Order Reliability Method (FORM), Second Order Reliability Method (SORM) and by numerical integration of the failure integral using Lepage's VEGAS algorithm. The results are shown in figure 8. The results were utilized for demonstrating that for the leakage size crack, the pipe design has high probability for leak before break. 


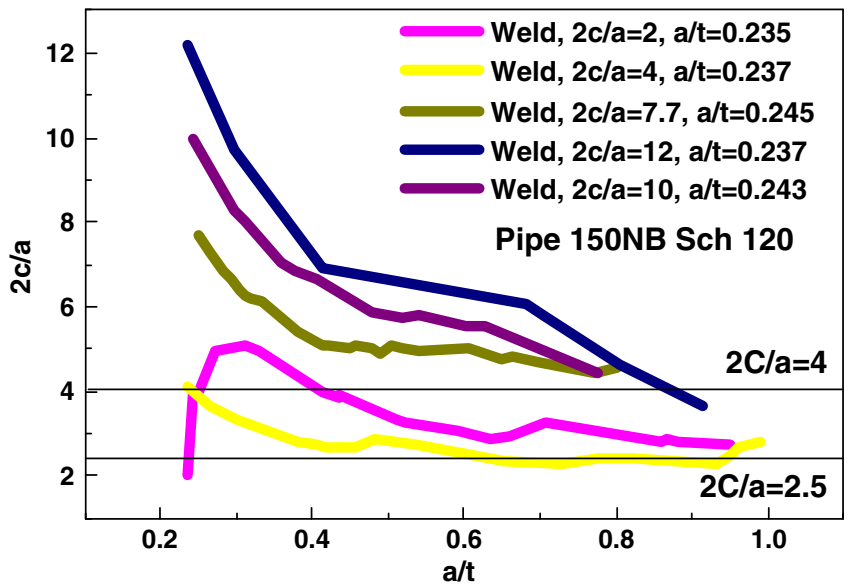

Figure 7. Final aspect ratio lies within 2.5-4.
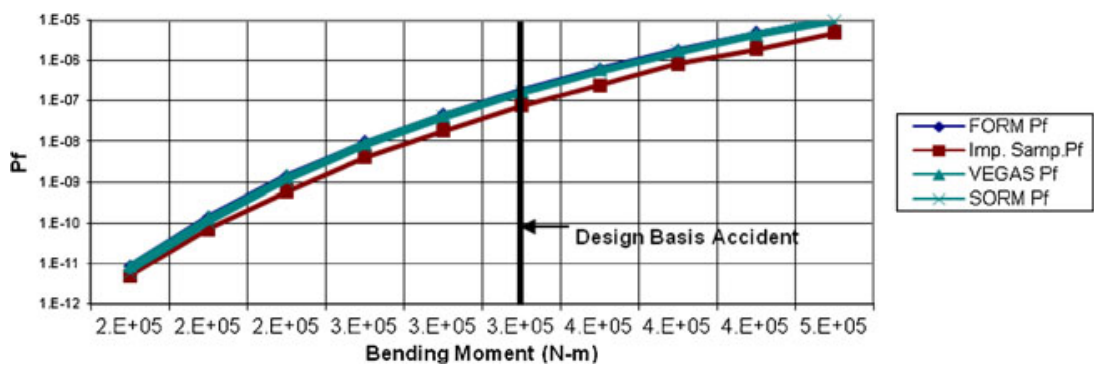

Figure 8. Probability of failure as a function of applied load.

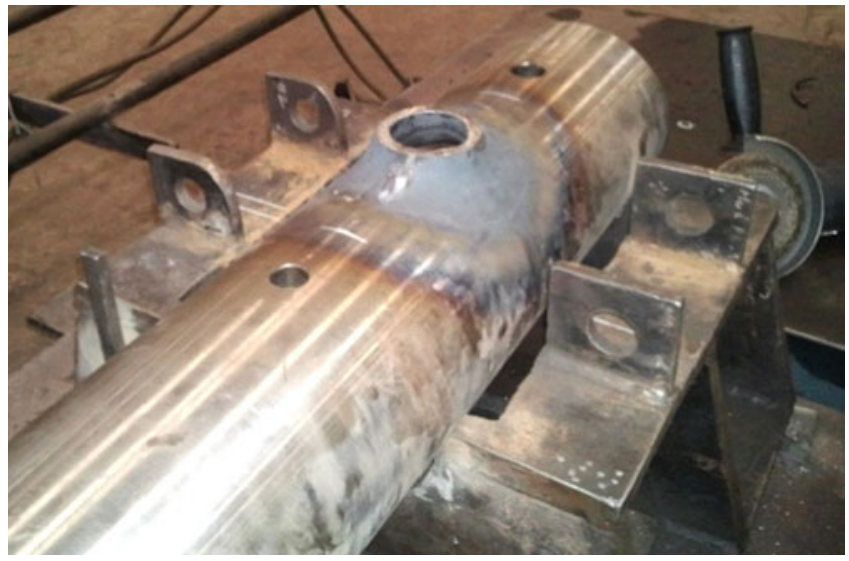

Figure 9. Pullout technology.

\subsection{Fatigue as a failure mechanism}

As seen from LBB stage 2 evaluation, fatigue resistance has been shown to be excellent. The areas most prone to fatigue are the discontinuities near welds. 
Fatigue life can be further improved if such discontinuities near shell-nozzle junctions can be avoided by providing a pull-out on the shell. Technology development undertaken in this direction for large thickness vessel has shown promising results. Figure 9 shows the technology demonstration of a pullout engineered on the inlet header of Advanced Heavy Water Reactor.

\subsection{Fracture behaviour}

Weld happens to be the critical location from fracture point of view. Fracture resistance of weld can be considerably improved by adopting Gas Tungsten Arc Welding (GTAW) in place of the conventionally used Shielded Metal Arc Welding (SMAW). The advantage of this process for welding of pipes of SS304LN material has been brought out by carrying out fracture tests on pipes welded using the two different techniques (figures 10, 11, 12, 13, 14, 15, 16 and 17).

It was also seen that hot wire GTAW with narrow gap technique is most desirable technique for welding of stainless steel pipes in terms of low residual stress, less sensitization and low embrittlement. The reduction in residual stress is due to the low heat input and sensitisation

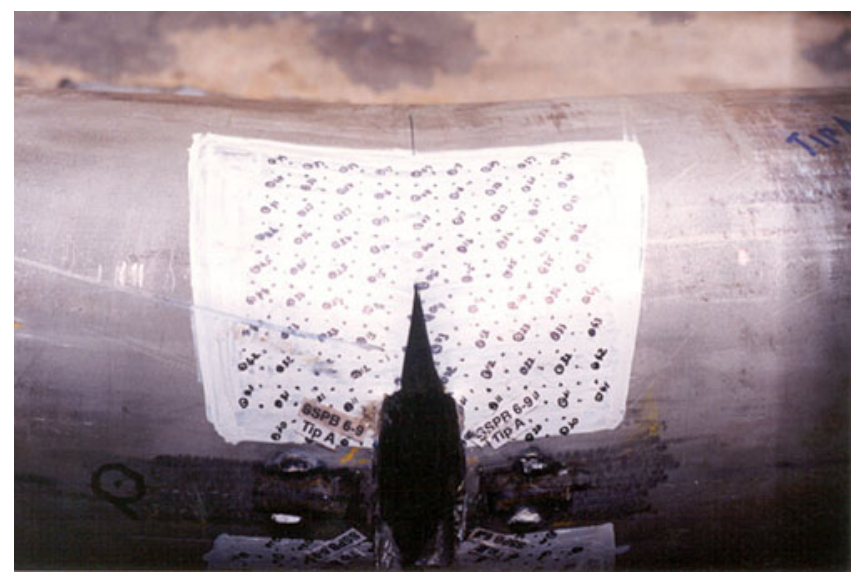

Figure 10. Pipe base - Very little tearing.

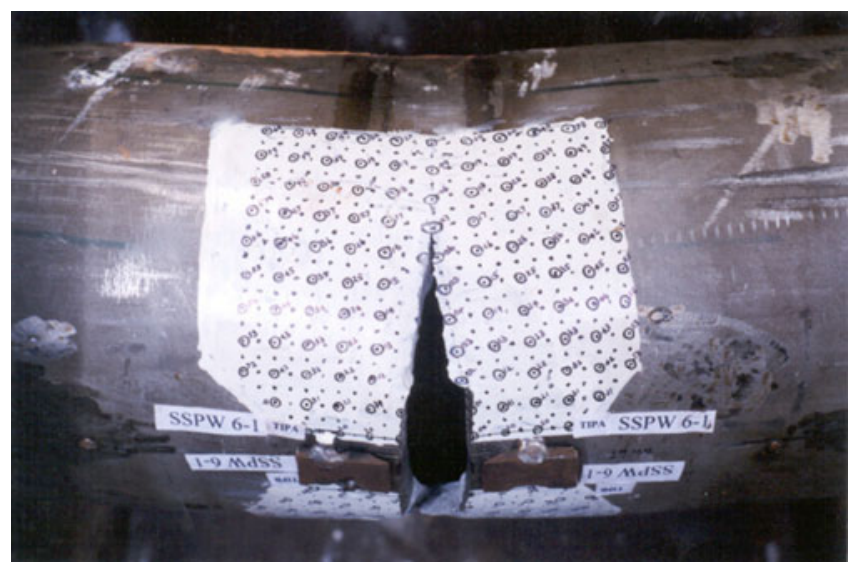

Figure 11. Pipe weld (GTAW) - Very little tearing. 


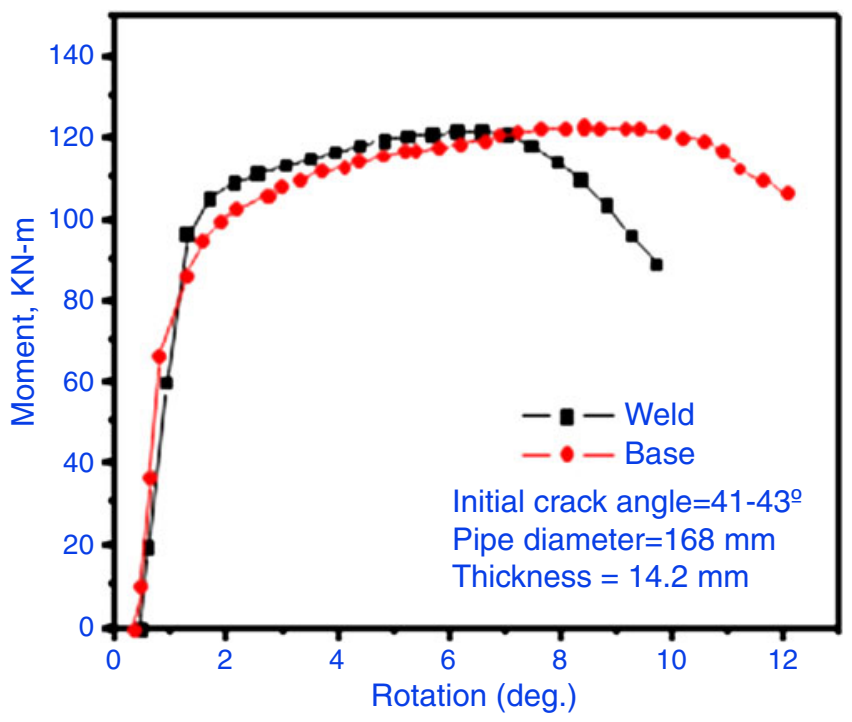

Figure 12. Comparison of moment vs rotation for base and weld.

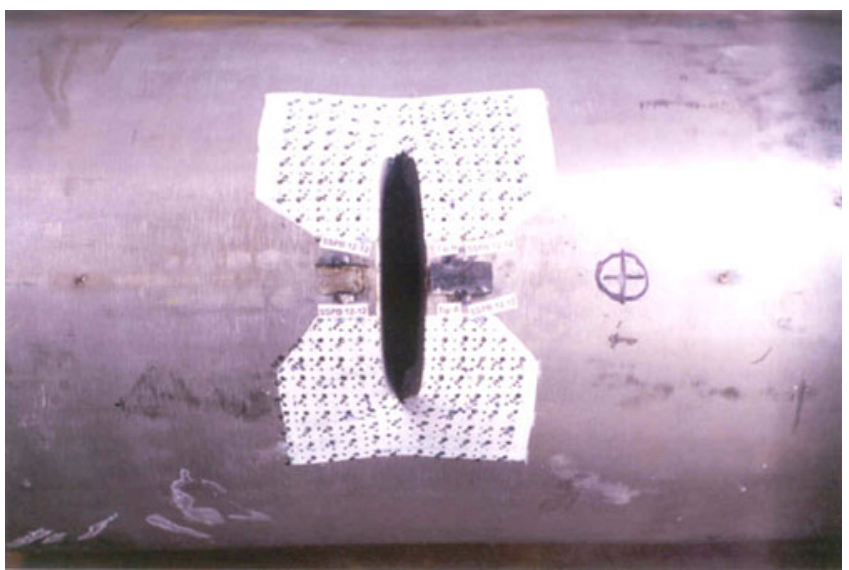

Figure 13. Pipe base - No tearing.

resistance is improved due to the high deposition rate welding (hot wire GTAW) and narrow gap technique leading to higher cooling rate (Singh et al 2008b).

\section{Seismic design considerations}

\subsection{AERB requirements (AERB Guide 2011, 2012)}

To mitigate the seismic hazard for protection of public and the environment, the NPP should be designed to withstand the effects of vibratory ground motion arising from strong earthquakes. 


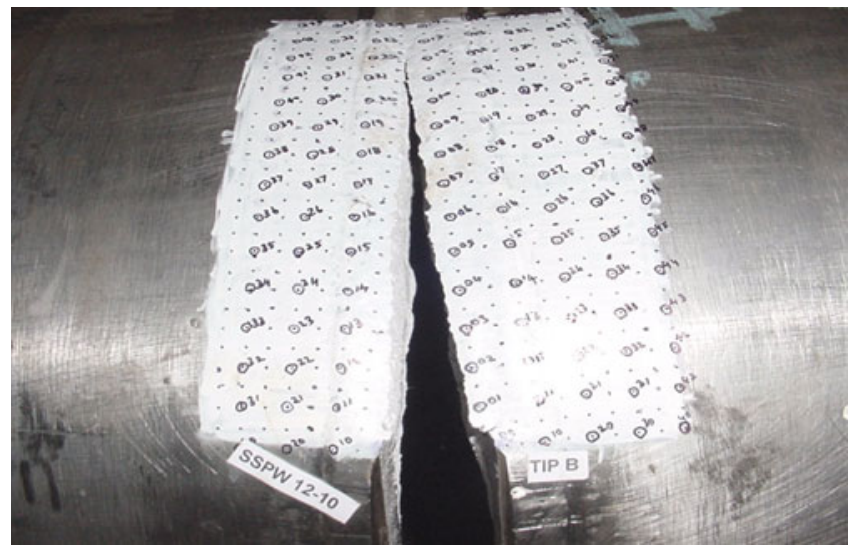

Figure 14. Pipe weld (GTAW + SMAW) significant tearing.

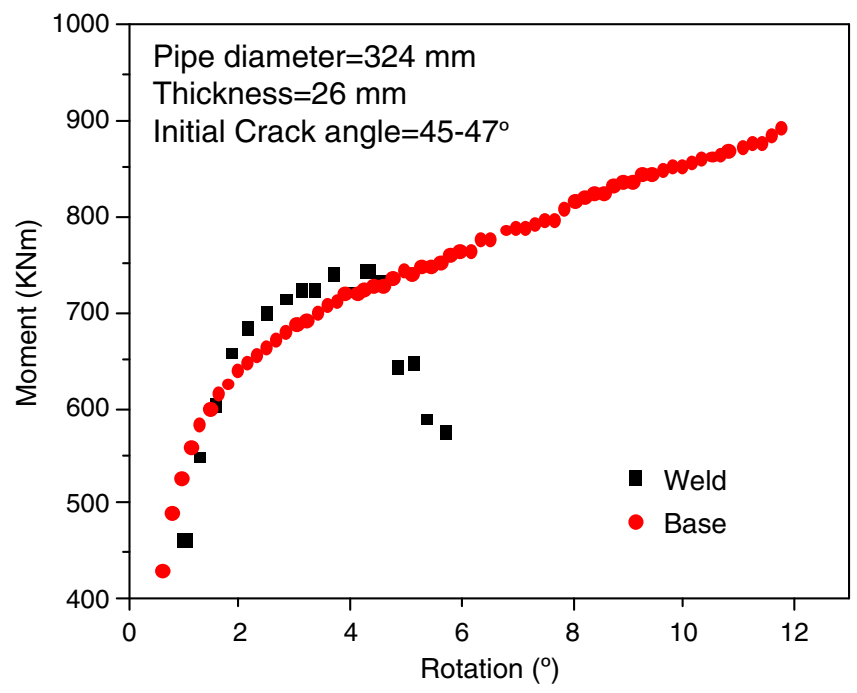

Figure 15. Comparison of moment vs rotation for base and weld.

The design basis ground motion for this purpose should be evaluated for each site. The Nuclear Power Plant should be designed for two levels of seismic ground motion.

The $\mathrm{S} 1$ level is the level of ground motion which can be reasonably expected to be experienced at the site area once during the operating life of the plant.

In the design of Nuclear Power Plant, the S1 level of earthquake should be the Operating Basis Earthquake (OBE). If S1 level of ground motion is exceeded at the site, the plant should be shut down. It will then be inspected to determine if any damage had occurred. The plant will be restarted after it is certified fit for operation.

The return period (mean recurrence interval) of the $S 1$ level event should not be less than 100 years when it is determined by a probabilistic method. 


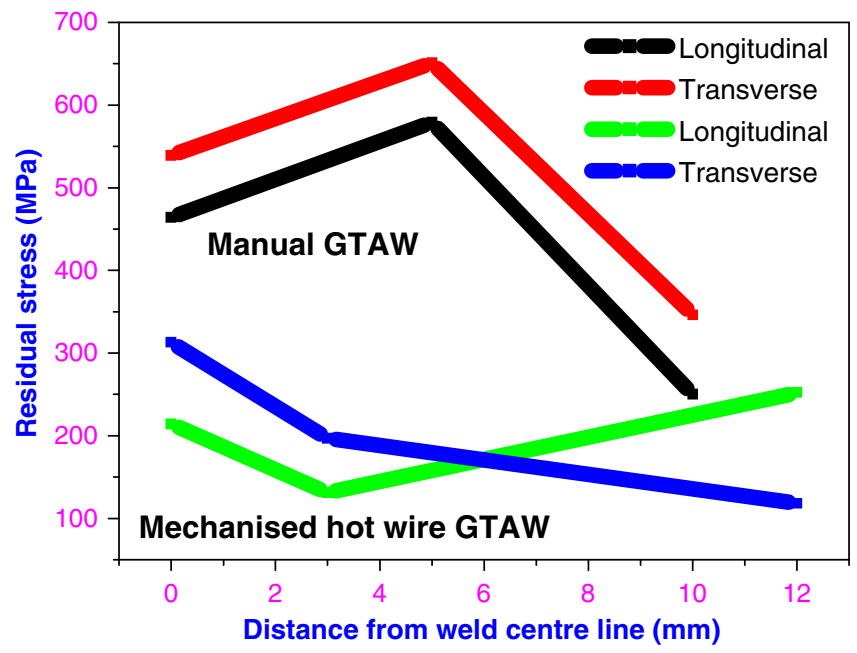

Figure 16. Residual stress in manual GTAW and hot wire GTAW.

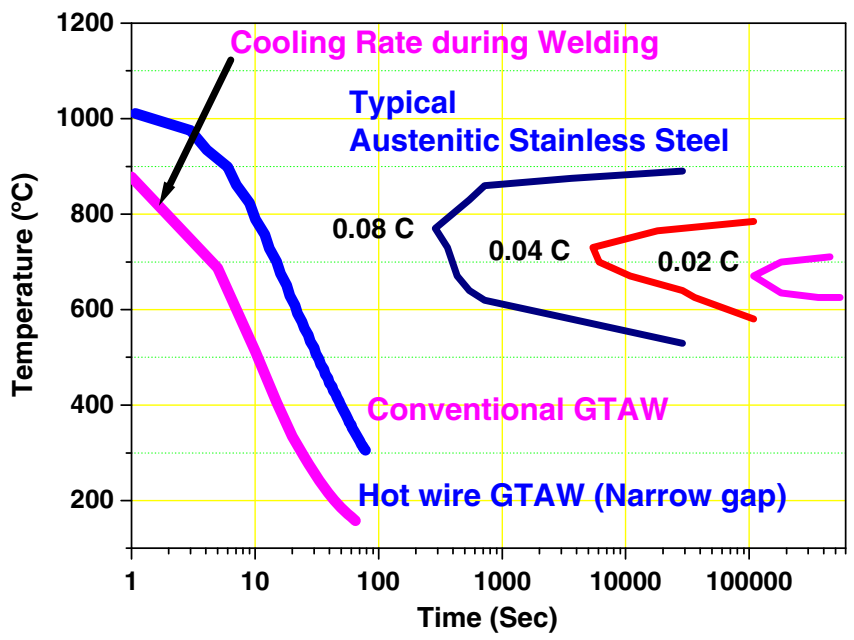

Figure 17. Temperature vs. time plot shows higher sensitization margin for narrow gap welding.

The S2 level ground motion is the maximum potential vibratory ground motion at the site based on the maximum earthquake potential of the (site) region. The S2 level motion will be fixed in accordance with the seismotectonic conditions in the region. A probabilistic evaluation may be carried out to demonstrate that the $\mathrm{S} 2$ level event has a return period of the order of 10,000 years.

In the event of occurrence of S2 level earthquake, it is required to ensure safe shutdown of nuclear power plant (NPP) and hence the S2 level motion is referred to as the safe shutdown earthquake (SSE).

In the design of a NPP, both S1 and S2 level earthquakes are explicitly considered under appropriate load combinations. 


\subsection{Design challenges}

The Advanced Heavy Water Reactor (AHWR) (figure 18) being designed by BARC has many passive safety features, the most prominent among them being the presence of large volume $\left(8000 \mathrm{~m}^{3}\right)$ of water at the top of the containment building in the form of a Gravity Driven Water Pool (GDWP). This water helps in removing decay heat from reactor when normal heat removal path is not available due to loss of external power and enables AHWR to tide over the station black out scenario, similar to Fukushima, for an extended period of about 100 days. Presence of such a large mass at high elevation raises a concern about its ability to withstand an earthquake (figure 19).

The solution was found by connecting the slab of the water pool to the inner containment building. The stiffness derived this way, lowers the time period of the structure, resulting in lower acceleration and hence lower stresses enabling the structure to withstand the earthquake event.

\subsection{Seismic margin assessment (Sharma et al 2013)}

Post Fukushima event, the regulatory requirements with respect to seismic and tsunami hazards were reviewed. The sites for Nuclear Power Plants (NPP) are evaluated based on criteria laid down in the AERB's 'Code of Practice on Safety in Nuclear Power Plant Siting'. The criteria, among others, include foundation conditions, seismicity, meteorological conditions, flooding, distance from airports/air corridors, industries handling toxic/ explosive substances, access by $\mathrm{road} / \mathrm{rail} / \mathrm{sea}$ and availability of land and cooling water, etc. Even though the requirements for siting and design of NPPs with respect to postulated design basis natural events were found to be sufficiently conservative, it was recognized that the magnitude of natural events can occasionally be higher than what is considered in design. Therefore, additional provisions are being made to further enhance the safety level of all NPPs. Automatic reactor trip on seismic signal is being implemented in all reactor units. Onsite AC power sources such as air cooled diesel generators

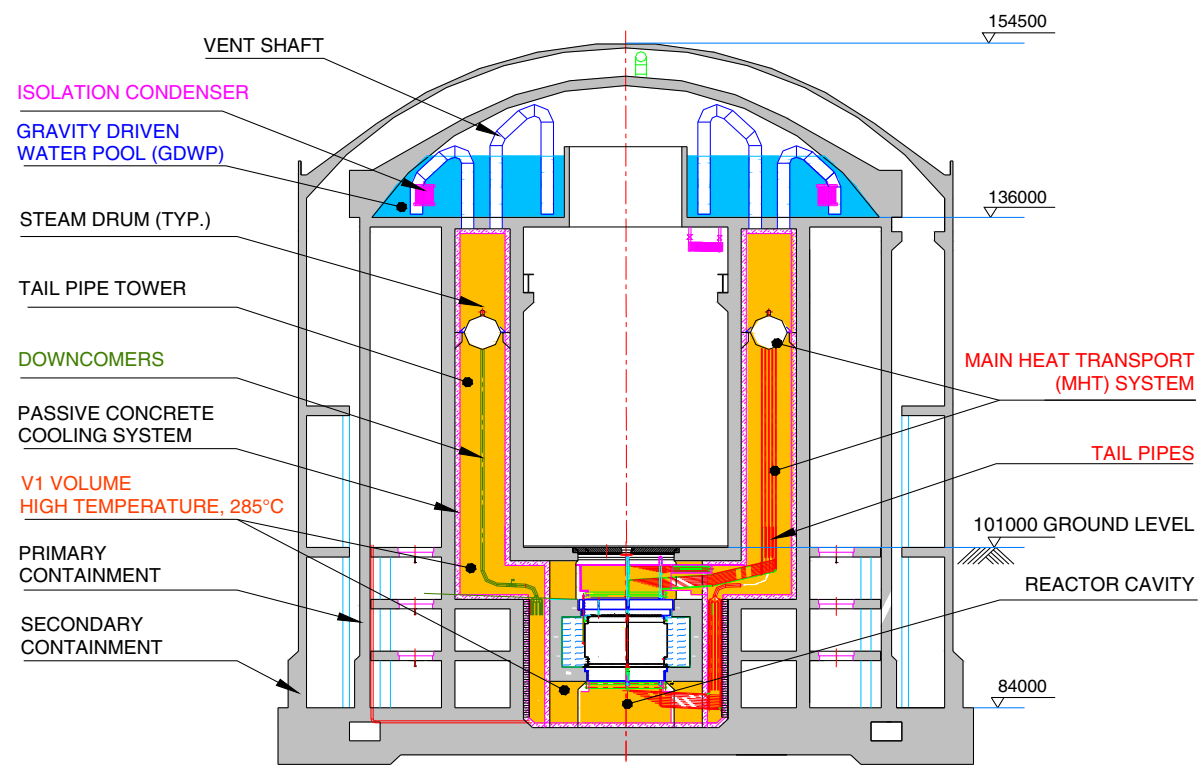

Figure 18. Schematic of the advanced heavy water reactor. 

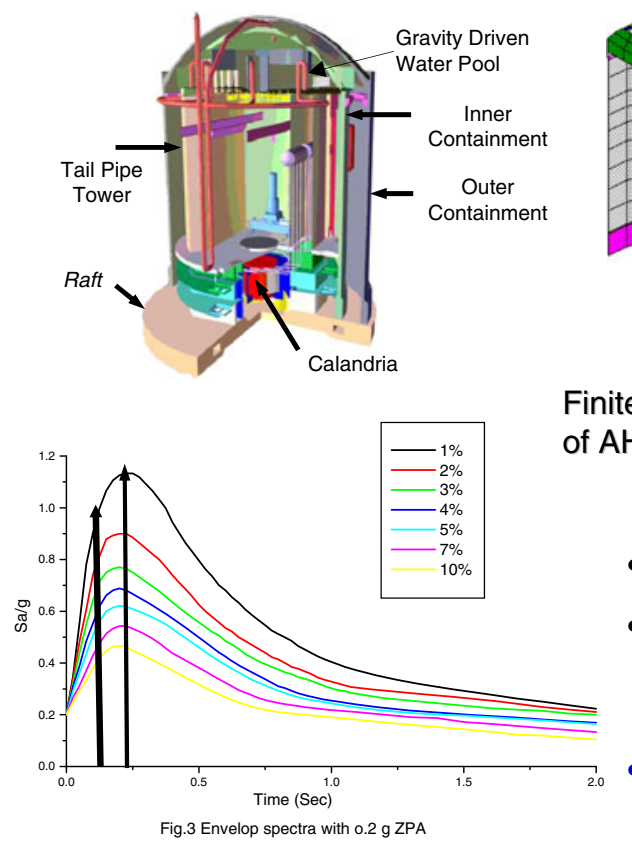

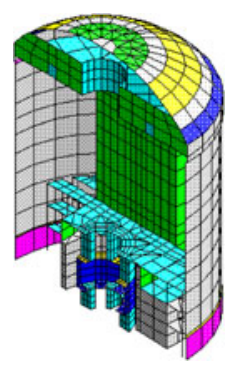

Finite Element Model of AHWR building

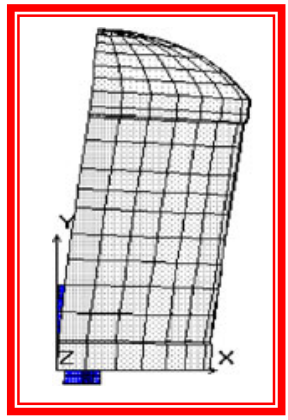

First mode shape

- Reactor Building needs seismic qualification

- Problem made severe by Gravity Driven Water Pool containing $8000 \mathrm{~m}^{3}$ of water at the top

- Solution - Connect GDWP to Reactor

Figure 19. Seismic analysis of GDWP.

are being provided to take care of extreme natural events. Augmentation of existing provisions like hook-up arrangements for addition of cooling water from external sources for decay heat removal for extended period, increasing battery life for monitoring important parameters, augmentation of water inventory and additional measures for protection of equipment as necessary are under implementation.

As a parallel measure, an exercise has been undertaken to assess the seismic margin available in structures designed to withstand a certain level of earthquake. Seismic Margin is defined as the ratio of Peak Ground Acceleration (PGA) of the earthquake corresponding to desired performance to the PGA of design earthquake. The desired performance can be linear, limited damage or collapse (figure 20).

\begin{tabular}{|c|c|c|c|}
\hline Performance & Linear $(\mathrm{L})$ & Limited damage (LD) & Collapse prevention (CP) \\
\hline $\begin{array}{l}\text { Level of damage } \\
\text { expected due } \\
\text { to earthquake }\end{array}$ & $\begin{array}{l}\text { Structure within } \\
\text { elastic range. } \\
\text { Ductility }=1.0 \\
\text { Structures requiring } \\
\text { leak tightness e.g. } \\
\text { containment }\end{array}$ & $\begin{array}{l}\text { Limited permanent } \\
\text { deformation. } \\
\text { Ductility }=2.5 \\
\text { (TECDOC } 1347 \text { 2003). } \\
\text { Safety related } \\
\text { structures }\end{array}$ & $\begin{array}{l}\text { No collapse but } \\
\text { significant damage. } \\
\text { Ductility }=4.0 \\
\text { (TECDOC 1347). } \\
\text { Conventional industrial/ } \\
\text { office buildings }\end{array}$ \\
\hline
\end{tabular}

For example, if margin is to be calculated for collapse:

Seismic margin against collapse $=\mathrm{PGA}_{\text {Collapse }} / \mathrm{PGA}_{\text {Design }}$ 


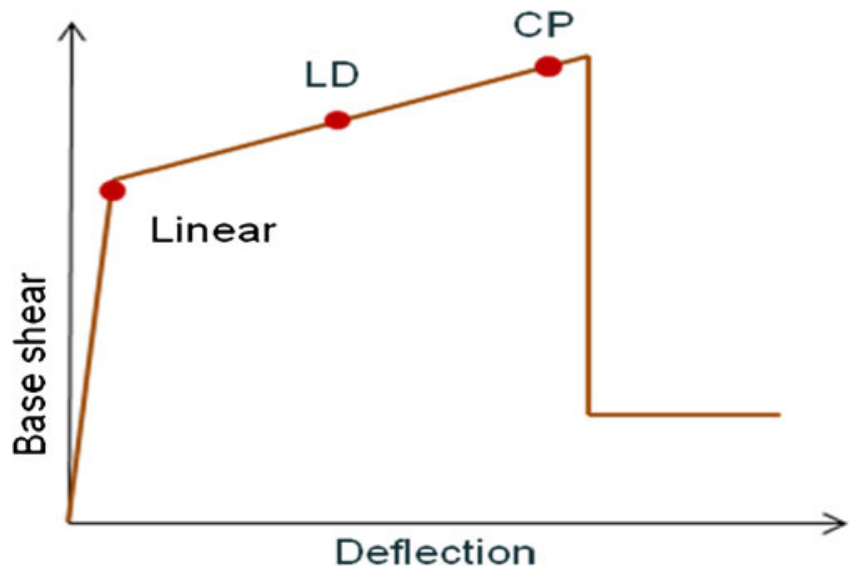

Figure 20. Seismic performance curve.

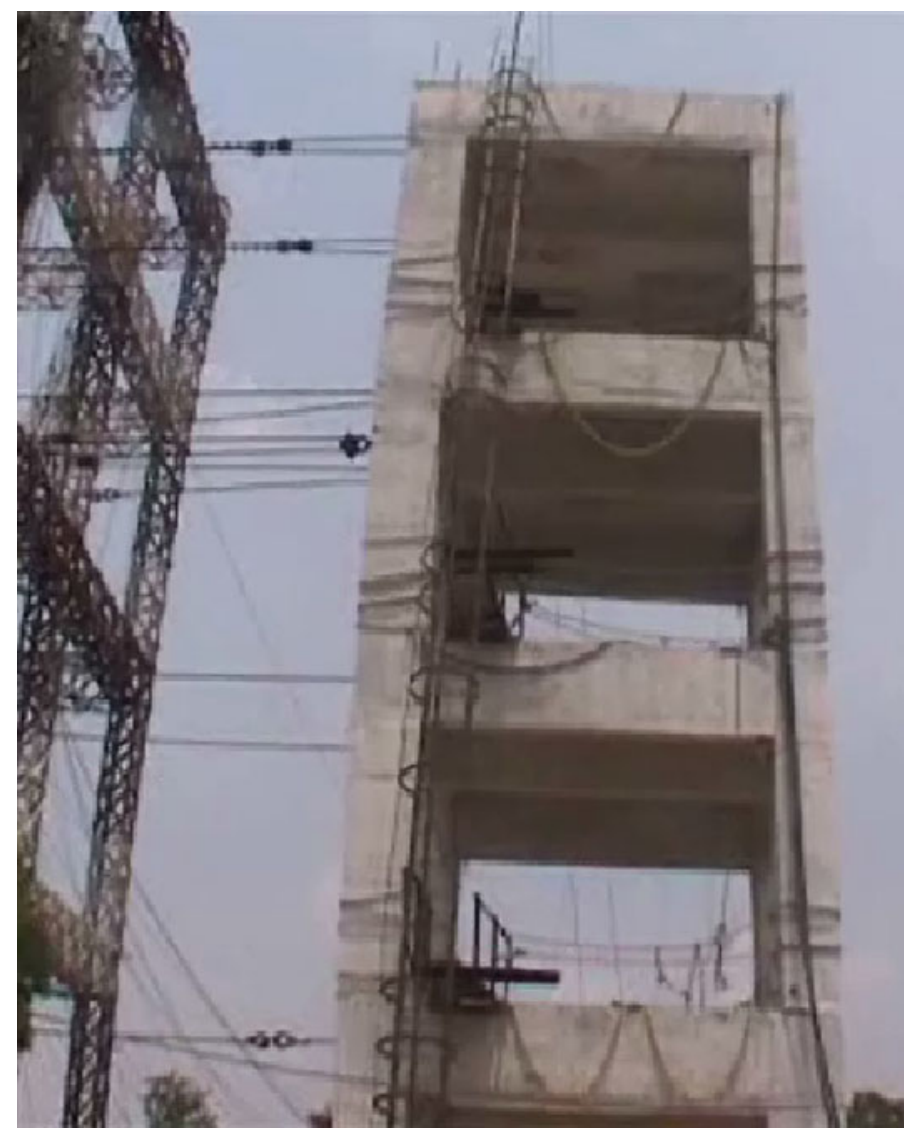

Figure 21. Building under pushover loading. 
To estimate the performance against any seismic level, pushover analysis or incremental hinge technique can be used. The performance point is the intersection of the capacity and the demand curves on spectral acceleration vs spectral displacement plot.

In order to provide experimental evidence of the margin, a full scale frame structure, designed for a PGA of $0.16 \mathrm{~g}$, was subjected to Pushover Test and its load-displacement characteristic was obtained. The load corresponding to 'limited damage' was found to correspond to PGA of $0.6 \mathrm{~g}$, showing a margin of 3.75 (figures 21 and 22).

\subsection{Base isolated buildings for large seismic margins}

The base isolation is aimed to attenuate the horizontal acceleration transmitted to the superstructure. The isolation system attempts to decouple the building or structure from the horizontal components of the ground motion by interposing structural elements with low horizontal stiffness between the structure and the foundation, which results the shifting of fundamental frequency of the structure out of the range of dominant earthquake energy and increasing the energy absorbing capacity.

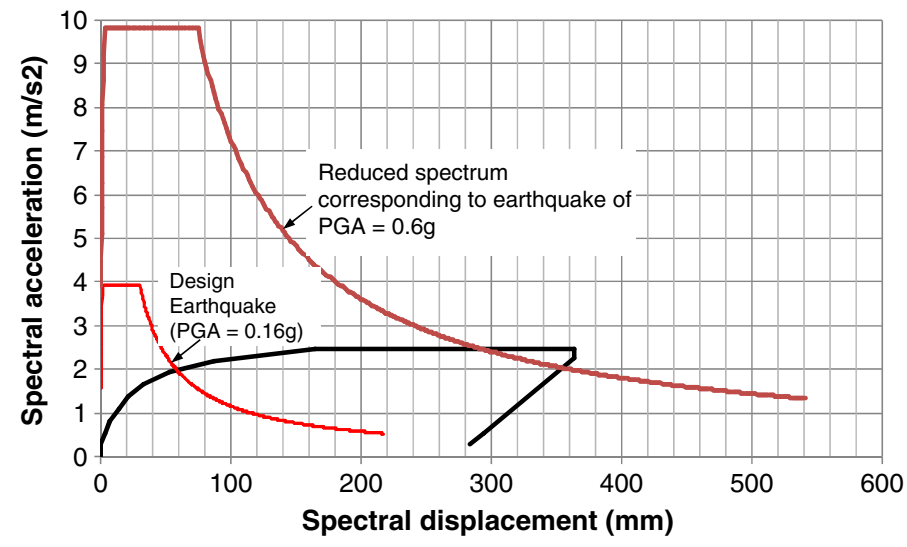

Figure 22. Seismic margin assessment.

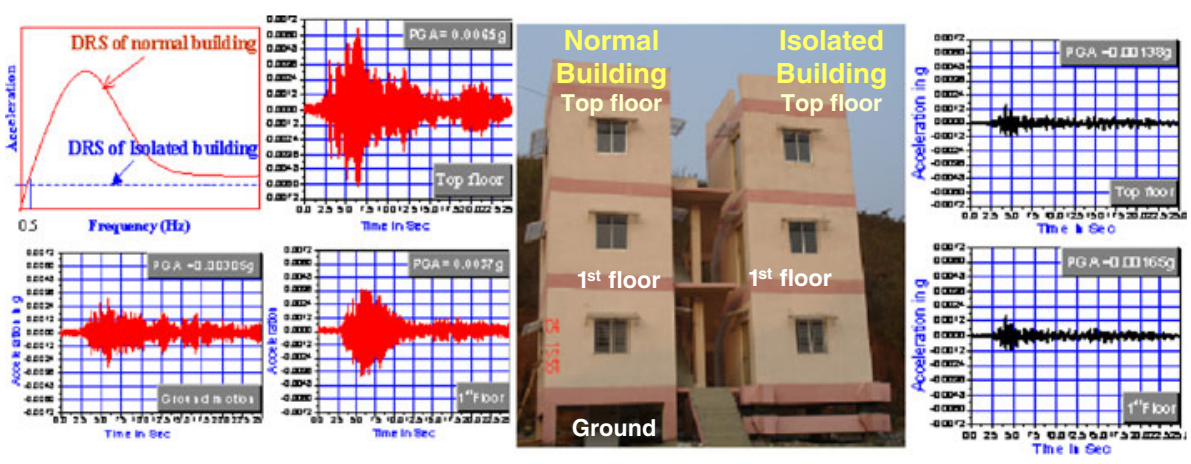

Figure 23. Base isolated building. 
To verify the effectiveness of base isolation under actual earthquakes, 2 three storey buildings were built as shown in the figure 23, one on regular foundation (fixed base) and other on base isolators. In the recent past these buildings have seen a few earthquakes. It can be seen from the recorded motions that in the building with regular foundation, the motion got amplified to a factor of 2.13, where as in base isolated building the motion is 0.3 times the maximum of base excitation. This shows clearly the effectiveness of base isolation (Mahadik et al 2011).

With this observation, it can be said that design of nuclear facilities on base isolation system will help to standardize the seismic design and also help in reducing the design cost of primary and secondary systems as well.

\subsection{Retrofitting}

In the event of a revision of the Design Basis Ground Motion, structure may not meet the code limits and retrofitting may become necessary. The most vulnerable location in the event of an earthquake is the beam-column joint. A particular form of retrofitting by way of employing 'Haunch Elements' (figures 24 and 25) has been experimentally evaluated. Following observations were made (Sharma et al 2010):

- As-built frame underwent undesirable failure modes such as beam-column joint failures at an excitation level of $0.5 \mathrm{~g}$ PGA,
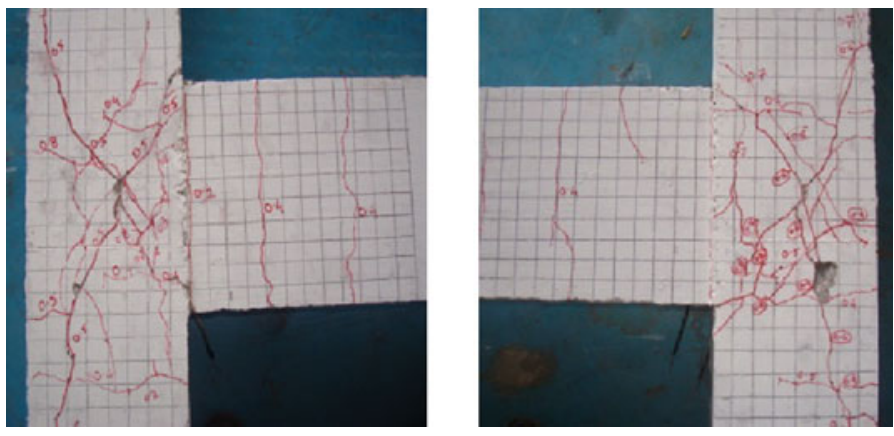

Figure 24. As built structure.
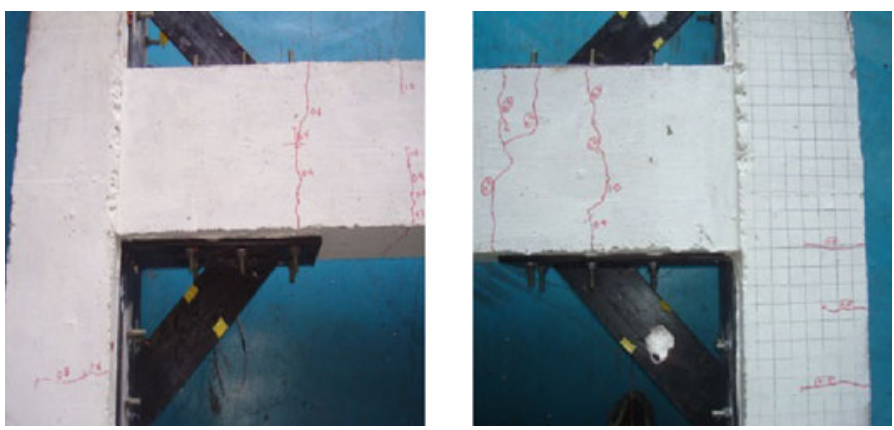

Figure 25. Retrofitted with Haunch Elements. 
- The retrofitted frame displayed desirable failure patterns such as ductile beam hinging. The retrofitted frame did not fail till the PGA of $1.0 \mathrm{~g}$.

- The tests clearly displayed the efficacy of the haunch retrofit solution improving the overall structural behaviour under seismic loads.

\subsection{Ratchetting considerations in seismic design}

ASME B\&PV Code Section III provides the stress limits for piping components that protect the structural integrity of the pressure boundary for reactor piping systems. In a reversible cyclic loading that occurs during seismic event, the failure of the pressurized piping is by incremental plastic collapse (ratcheting) and low cycle fatigue and not by the static plastic collapse. When a piping component is subjected to constant internal pressure and cyclic bending moment, the circumferential strain tends to get accumulated in every cycle, leading to a bulge in the pipe and subsequent rupture due to thinning after certain number of cycles.

The conservatism in the design rules leads to excessive piping supports to accommodate infrequent dynamic loads (over restraint system), which can lead to higher thermal stress.

In view of the above, ASME code increased the allowable value for this type of loading. To verify the applicability, it was decided to study the phenomenon by conducting experiments on straight pipes and elbows by subjecting them to constant internal pressure and a cyclic bending moment in a loading frame (Gupta et al 2002). A typical elbow test and strain accumulation can be seen in the figures 26 and 27.

- In all the tests, the elbows could withstand a large number of cycles, there was extensive ballooning, a crack got initiated on the inside surface due to fatigue-ratchetting, grew to become a throughwall crack producing leakage.

- A piping loop subjected to a shaketable test, could withstand a large number of earthquake events.

- The tests have confirmed that the failure mode under seismic loading is fatigue-ratchetting and the limits of ASME code are conservative.

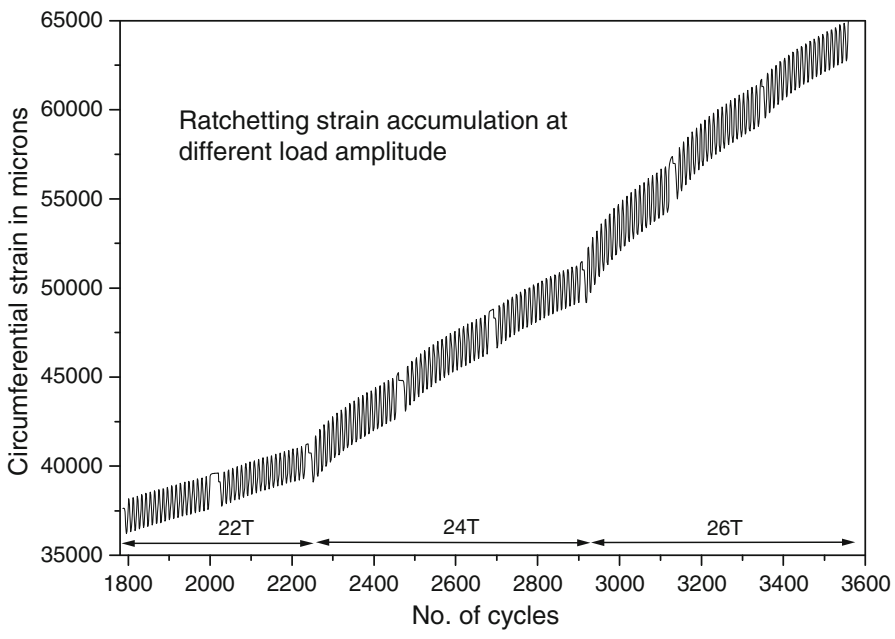

Figure 26. Strain accumulation with number of cycles. 
A piping loop was also subjected to shaketable motions (figure 28) of increasing amplitude starting from $0.5 \mathrm{~g}$, each level comprising of 9 passes each of $30 \mathrm{~s}$ duration. Failure took place at a weld at ' $\mathrm{g}$ ' level equal to $0.8 \mathrm{~g}$ after more than 30 passes at different ' $\mathrm{g}$ ' levels.

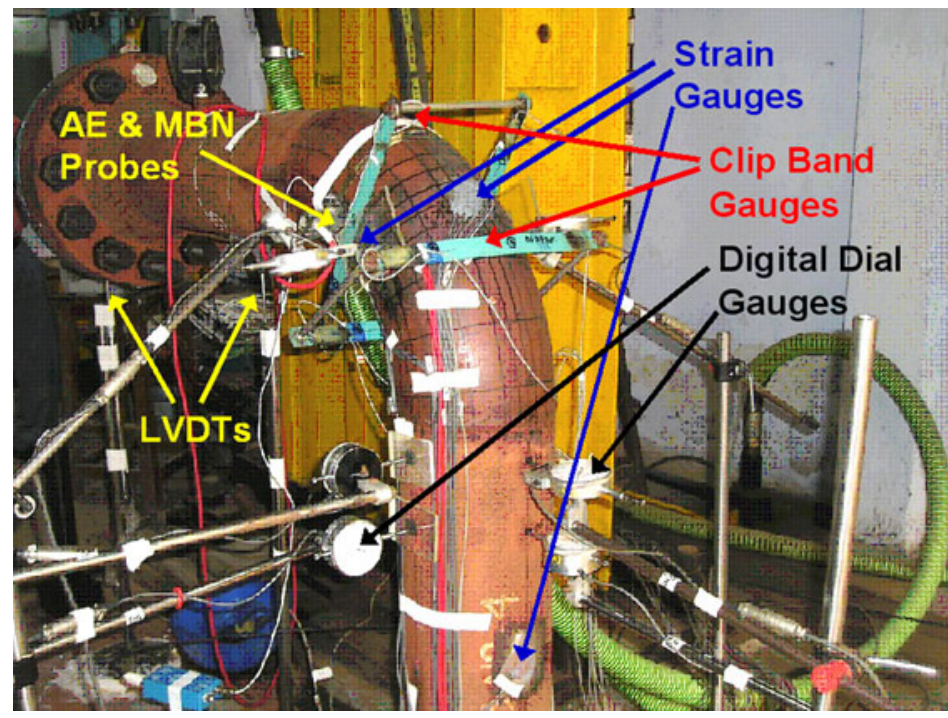

Figure 27. Elbow being subjected to ratchetting test.

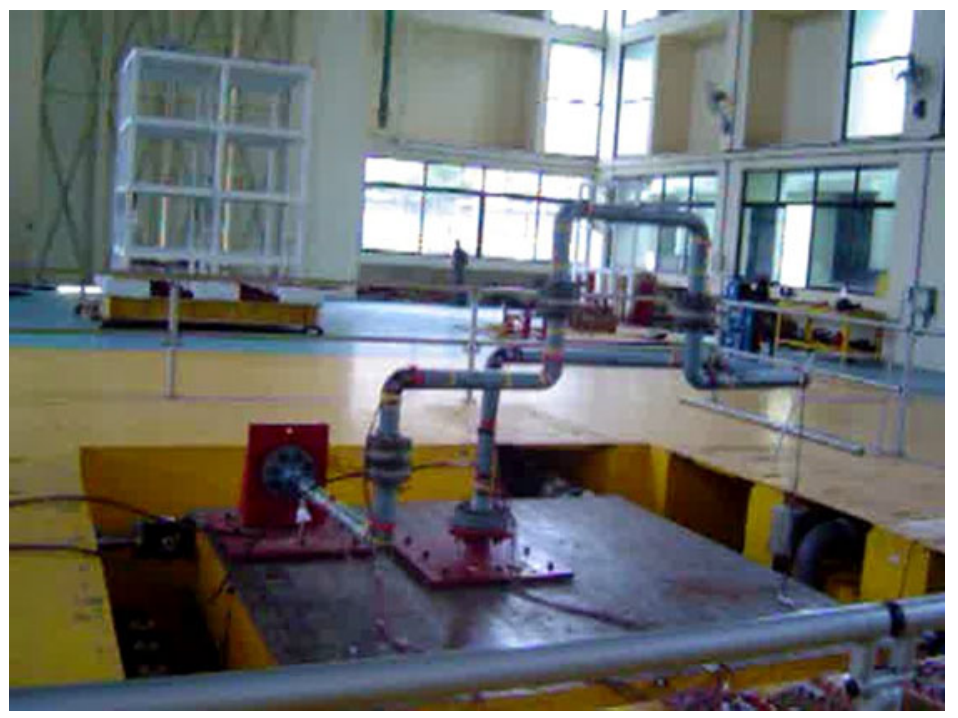

Figure 28. A piping loop tested on a shaketable. 
To account the ratcheting strain effect on fatigue-life with mean stress, i.e., fatigue-ratcheting synergy, the standard equation used for predicting fatigue life needed to be modified by inclusion of $\sigma_{m}$ and $\varepsilon_{r}$ as follows:

$$
\frac{\Delta \varepsilon}{2}=\frac{\left(\sigma_{f}^{\prime}-\sigma_{m}\right)}{E}(2 N)^{b}+\left(\varepsilon_{f}^{\prime}-\varepsilon_{r}\right)\left(\frac{\sigma_{f}^{\prime}-\sigma_{m}}{\sigma_{f}^{\prime}}\right)^{\frac{c}{b}}(2 N)^{c} .
$$

\section{Containment building}

\subsection{Internal pressurization}

In the event of unlikely occurrence of the postulated loss of coolant accident (LOCA), when severance of the primary coolant piping takes place; the radioactivity can get released out into the primary containment, which is designed to withstand the pressure, temperature and other loads consequent to the occurrence of an accident. Containment is the ultimate physical barrier between radioactive source inside the nuclear reactor core and the public at large.

In order to establish the ultimate load carrying capacity of the containment building, a 1:4 scale model of the containment building has been built at Tarapur (figure 29). BARC Containment (BARCOM) Test-Model at Tarapur was subjected to an over-pressure test up to 1.77 times design

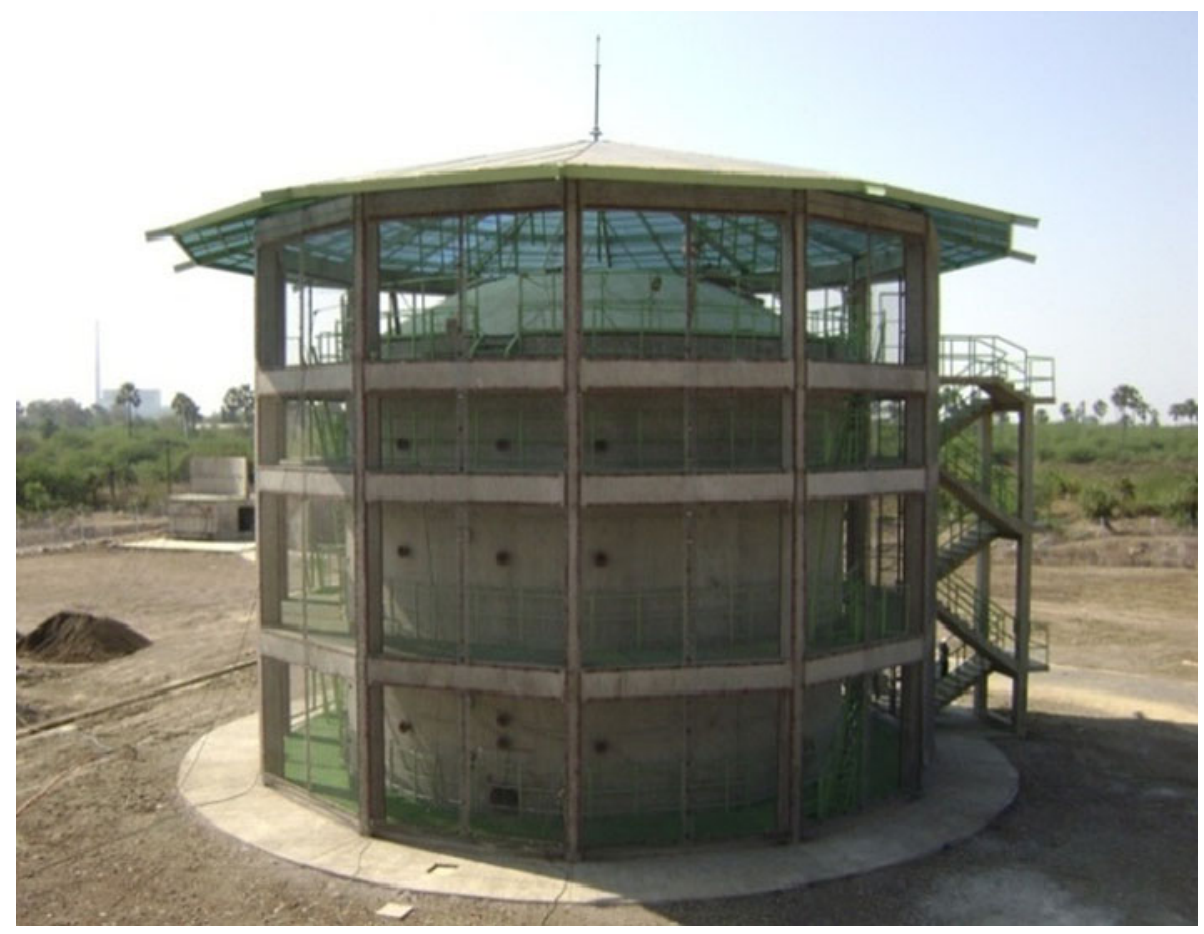

Figure 29. (BARCOM) test-model. 
pressure, when the first milestone 'first appearance of crack' was reached (Parmar et al 2011). This was inferred by strains monitored with embedded sensors entering the inelastic regime and later confirmed by leak detection and visual inspection. Leakage rate estimation at various stages during depressurization shows that BARCOM Test model regains its leak tightness at lower pressures even after the Over-pressurization Test (OPT) up to 1.77 Pd due to residual pre-stress of tendons even in the cracked condition; thus demonstrating built-in capacity to hold the released fission products besides assuring reserved structural margin for Indian PHWR Containments.

The model will be further pressurized after attending to leaks to assess margin against structural failure.

\subsection{Reliability of nuclear power plant containment under accidental internal pressure}

Structural reliability of typical inner containment of a nuclear power plant under overpressurization against different failure stages i.e., crack initiation, yielding of rebar and tendon was carried out considering variability in material properties of concrete and steel, and LOCA pressure (Anand et al 2007). Response surface methodology was used to formulate limit state functions for different failure stages. First Order Reliability Method (FORM) is applied to evaluate probability at different failure stages. The probability of initiation of crack at design pressure is of the order of $10^{-4}$ per occurrence of the pressure of the magnitude of design pressure (figure 30). The safety margin on design pressure is calculated using HCLPF (high confidence low probability of failure) values. This pressure was estimated to be 1.4 times the design pressure. Thus the reliability analysis shows that additional safety margin exists compared to what is envisaged in deterministic design. Probability of plastic strain in rebar/tendon exceeding limiting value of $0 \%$ to $5 \%$ was obtained and plotted in figure 31 . The failure probability is conditional with respect to the existence of LOCA. The probability of failure, while considering $0.5 \% /-5 \%$ yielding in tendon or rebar is calculated as $2 \times 10^{-6}-6 \times 10^{-7}$ per occurrence of design pressure.

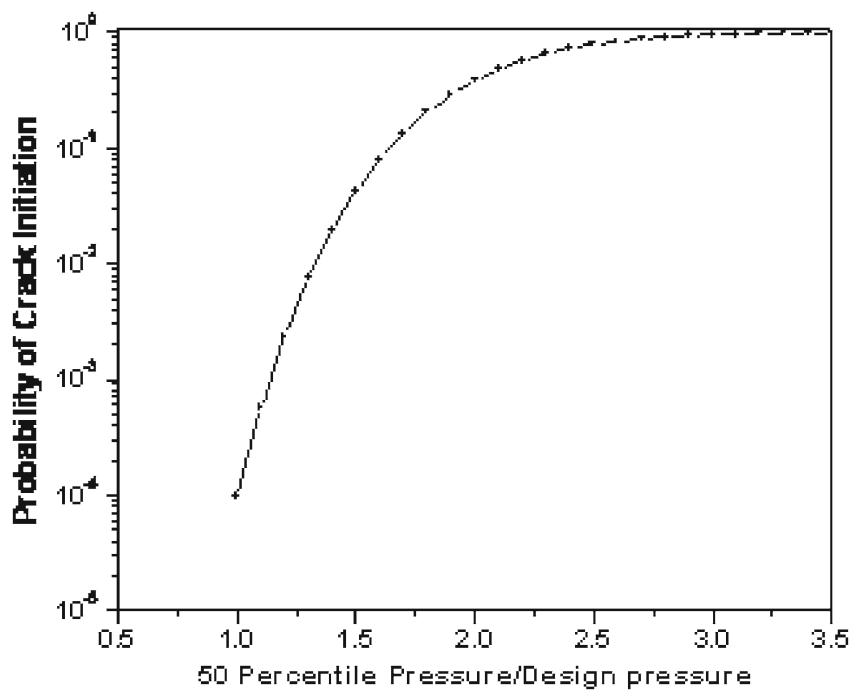

Figure 30. Probability of crack initiation at cylindrical wall against pressure. 


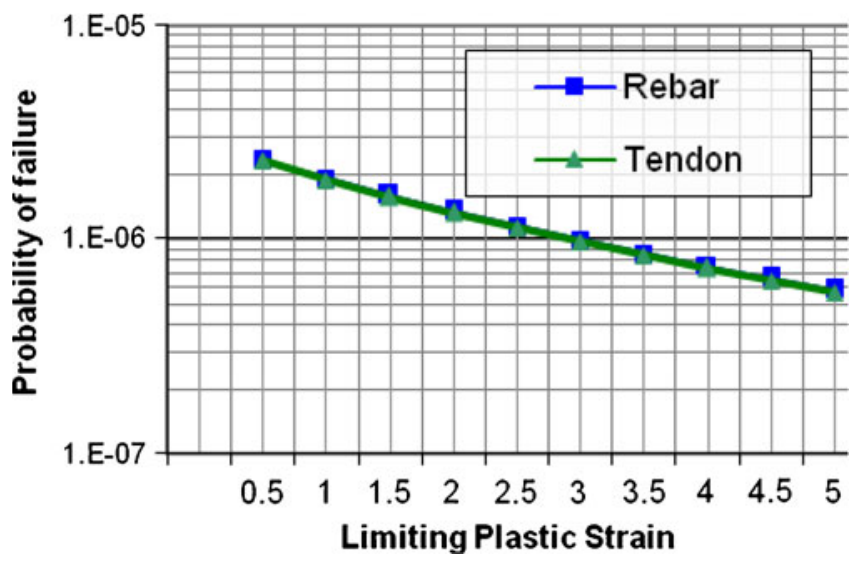

Figure 31. Probability of failure.

\subsection{Aircraft impact (Kukreja et al 2003)}

Protection of plant against the effect of aircraft impact on the nuclear power plant is considered right from the stage of site selection. Large aircraft impact is eliminated as a design basis because yearly probabilities of occurrence for sites more than 5 miles from the airport are less than $10^{-7}$. The reactor itself is housed in a containment building, which provides protection against external missiles, explosions, etc. The containment building is surrounded by other structures making it almost impossible for an aircraft to strike it. These provisions make the event of aircraft impact a beyond-design-basis accident.

However, even for a beyond-design-basis accident the capability of the containment building to withstand the aircraft impact has been evaluated. Indian PHWRs have a primary inner containment (IC) of pre-stressed construction, designed to withstand the pressure rise due to a
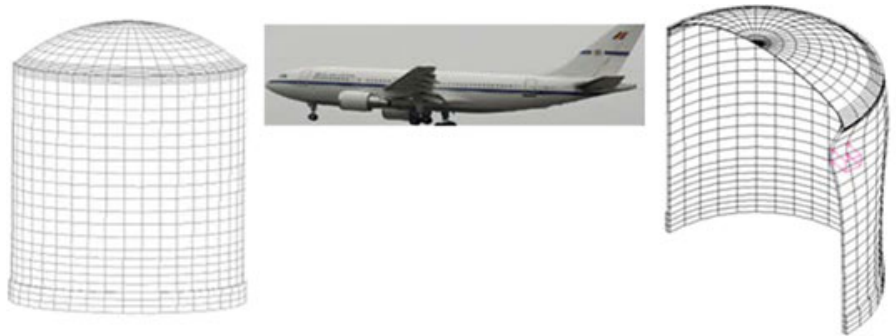

\section{Deformed Shape of OCW}
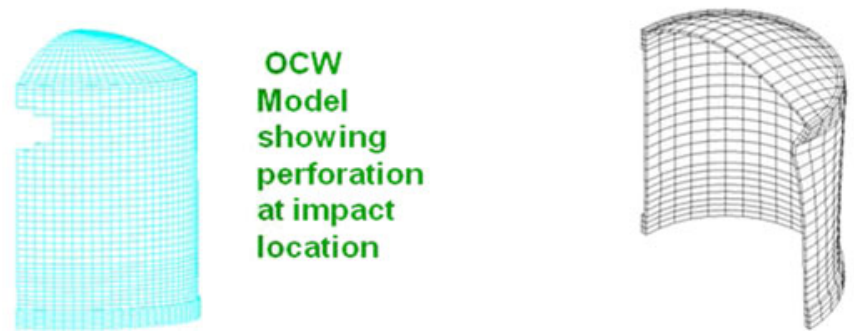

Deformed Shape of ICW

Figure 32. Modelling to demostrate the safety of containment against aircraft impact. 
postulated loss of coolant accident. The outer containment (OC) completely envelops the inner containment. This arrangement helps in resisting the aircraft impact.

Non-linear transient dynamic analysis of 500 MWe PHWR containment structure has been carried out for Boeing 707-320 aircraft impact with simulation of cracking, crushing and rebar yielding. The analysis results show that the $\mathrm{OC}$ will undergo local damage leading to perforation in the OC during impact and a significant amount of impulsive load would be absorbed by this first barrier. Subsequently, the impact load will be transferred to the IC, which is of larger thickness with pre-stressed construction. Further, it was observed that there would be local cracking and rebar yielding in IC but there would be no perforation.

Thus it has been demonstrated that the double wall of OC and IC would be capable of sustaining the full impulsive load of Boeing 707-320 aircraft (figure 32).

\section{Ageing}

Structural integrity is affected by defects/deformations induced during service and also by degradation of material during service. Possibility of excessive deformation or generation of defects such as cracks is adequately addressed by the design rules which consider time dependent failure modes such as creep, fatigue. Corrosion is prevented by control of chemistry of the environment. All possible material degradation mechanisms such as embrittlement, metallurgical changes are also considered during design.

Nevertheless, provision is made for in-service inspection to ensure that the degradations are under control.

Specific provisions such as ultrasonic inspection of all the welds every 10 years and thickness measurement at all the locations prone to flow accelerated corrosion can be cited in this regard.

\section{Conclusions}

- Structural safety has been receiving the due importance that it deserves by way of safety classification, adoption of appropriate design codes, consideration of all design basis events, detailed stress analysis, stress categorization and load combination.

- The applicability of the principle of leak-before-break has been demonstrated by performing a large number of fatigue and fracture on full scale piping components.

- In the light of the Fukushima accident, special efforts are put in place to assure structural integrity in a seismic event. In spite of the fact that the current regulatory requirements for siting and design of NPPs with respect to postulated design basis natural events were found to be sufficiently conservative, seismic margin assessment is being carried out for the beyond design basis earthquake. The tests carried out on structures and piping have shown existence of considerable margin above the level of earthquake considered in design. Phenomena such as ratcheting have been addressed explicitly by carrying out tests on piping components and by shaketable tests on piping loops and shown to be not of major concern.

- The containment building, which is the ultimate barrier between radioactive source inside the nuclear reactor core and the public at large, has been assessed for overpressurisation and a margin of at least 1.77 over design pressure has been demonstrated. Leakage rate estimation at various stages during depressurization shows that BARCOM Test model regains its leak tightness at lower pressures even after the Over-pressurization Test (OPT) up to $1.77 \mathrm{Pd}$ due to residual pre-stress of tendons even in the cracked condition; thus demonstrating 
built-in capacity to hold the released fission products besides assuring reserved structural margin for Indian PHWR Containments.

- It is also shown that under a postulated aircraft impact; while the outer containment will be perforated; the damage to inner containment will be confined to rebar yielding and local cracking and there will be no perforation.

- Although all the important aspects of structural safety have been covered, it is recognized that safety is a moving target and a conscious effort is made to achieve higher safety standards.

\section{Acknowledgements}

The author gratefully acknowledges the contributions of the following scientists of Reactor Design \& Development Group, BARC: Dr. R.K. Singh, Dr. G.R. Reddy, V. Bhasin, R. Rastogi, P.K. Singh, Dr. J. Chattopadhyay, S.K. Gupta, P.N. Dubey, Dr. P.K. Vijayan, D.K. Nathani.

\section{References}

AERB Code No. AERB/SC/S 2013 Code of practice on safety in nuclear power plant siting

AERB Guide No. AERB/SG/S-11 2011 Seismic Studies and Design Basis Ground Motion for Nuclear Power Plant Sites, Atomic Energy Regulatory Board

AERB Safety Guide No. AERB/SG/D-5 2000 Design Basis Events for Pressurised Heavy Water Reactor, Atomic Energy Regulatory Board

Anand V, Rastogi R, Bhasin V, Vaze K K, Ghosh A K and Kushwaha H S 2007 Structural reliability evaluation of AHWR inner containment under over-pressurization. Transactions, SMiRT 19, Toronto, August, Paper \# M05/3

ASME B\&PV Code, Sec. III Div. 1, Rules for Construction of Nuclear Facility Components

Chattopadhyay J, Dutta B K and Vaze K K 2011 Development of new correlations for improved integrity assessment of nuclear reactor piping components. 21st International Conference on Structural Mechanics in Reactor Technology, SMiRT 21, New Delhi, India

Gupta S K, Bhasin V, Vaze K K and Kushwaha H S 2002 Effect of earthquake loads on LBB assessment of high energy piping. $1^{\text {st }}$ National Conference on Nuclear Reactor Safety, November 25-27, Mumbai

IAEA 2013 Safety Classification of Structures, Systems and Components in Nuclear Power Plants, DRAFT SAFETY GUIDE DS367

IAEA-TECDOC-1347 2003 Consideration of external events in the design of nuclear facilities other than nuclear power plants, with emphasis on earthquakes

Kukreja M R, Singh R K, Vaze K K and Kushwaha H S 2003 Damage evaluation of 500 MWe Indian pressurized heavy water reactor nuclear containment for aircraft impact. SMiRT-17, Prague, August 1722 (Division J)

Mahadik V K, Paul D K, Reddy G R, Dubey P N and Deb S K 2011 Comparison of recorded response of conventional and base isolated buildings with analysis. Transactions, SMiRT 21, 6-11 November, New Delhi, India

Milne I, Ainsworth R A, Dowling A R and Stewart A J 1986 Assessment of the integrity of structures containing defects. CEGB Report, Central Electricity Generating Board, U. K., R/H/R6-Rev3

Parmar R, Singh T, Thangamani I, Trivedi N and Singh R K 2011 Over-pressure test on BARCOM prestressed concrete containment', Paper-486, Division V. SMIRT-21, New Delhi, 6-11 November

Raghava G, Gandhi P, Pukazhendhi D M, Sarvanan M, Vishnuvardhan S, Chattopadhyay J, Sahu M K and Dutta B K 2008 Internal pressure and high temperature fracture studies on carbon steel pipes. Proceedings of Sixth Structural Engineering Convention, SEC

Rastogi R, Bhasin V, Vaze K K and Kushwaha H S 2001 Theory and Verification Manual for BARC-R6 Software, BARC/2001/E/001 
Rastogi R, Jadhav P, Bhasin V, Vaze K K, Ghosh A K and Singh R S 2004 Probabilistic leak before break evaluation of straight pipes of primary heat transport piping of Tarapur $3 \& 4$ NPP. National Conference on Aging Management of Structures, System and Components, December 15-17, Mumbai, India

Sharma A, Genesio G, Reddy G R, Eligehausen R, Pampanin S and Vaze K K 2010 Experimental investigations on seismic retrofitting of reinforced concrete beam-column joints, Paper No A 007. 14 ${ }^{\text {th }}$ Sym on Earthquake Engg, IIT Roorkee

Sharma A, Reddy G R, Vaze K K and Eligehausen R 2013 Seismic assessment of full scale non-seismically detailed rc structure by pushover method - experiment and analysis. Eng. Struct. 46: 218-233

Singh P K, Bhasin V, Vaze K K, Ghosh A K, Kushwaha H S, Gandhi P, Murthy D S R and Sivaprasad S 2008a Fatigue studies on carbon steel piping materials and components: Indian PHWRs. Nucl. Eng. Des. 238(4): 801-813

Singh P K, Bhasin V, Vaze K K, Ghosh A K and Kushwaha H S 2008b Structural integrity of main heat transport system piping of AHWR. BARC Newsletter Issue No. 299 